\title{
Extracorporeal Membrane Oxygenation, Extubation, and Lung-Recruitment Maneuvers as Rescue Therapy in a Patient With Tracheal Dehiscence Following Slide Tracheoplasty
}

\author{
Jenni Raake MBA RRT-NPS, BethAnn Johnson MD, Brandy Seger RRT, Peter B Manning MD, \\ Pirooz Eghtesady MD, Paul Boesch MD, Michael Rutter MD, Amanda Woodard RN, and \\ Ranjit S Chima MD
}

\begin{abstract}
Long-segment congenital tracheal stenosis is characterized by complete tracheal rings. Surgery is required during infancy to optimize outcomes, and the post-surgery complications include mucus plugging, airway trauma, dehiscence at the surgery site, and death. We report a 5-week-old patient who developed a tracheal-wall dehiscence after a slide tracheoplasty. To safeguard against further dehiscence and to protect her one functional lung, we used extracorporeal membrane oxygenation (ECMO). After she was stabilized on veno-arterial ECMO we extubated and continued ECMO for 5 days. On postoperative day 14 we removed the ECMO and transitioned her to high-frequency oscillatory ventilation, and performed slow lung-recruitment maneuvers every 2 hours. This strategy of ECMO with extubation, then high-frequency oscillatory ventilation is a useful rescue therapy in patients with postoperative tracheal dehiscence. Key words: slide tracheoplasty; extracorporeal membrane oxygenation; ECMO; surgical wound dehiscence; tracheal stenosis; lung-recruitment maneuver; pulmonary agenesis. [Respir Care 2011;56(8):1198-1202. (C) 2011 Daedalus Enterprises]
\end{abstract}

\section{Introduction}

Long-segment congenital tracheal stenosis is a rare condition characterized by airway narrowing due to complete

\footnotetext{
Ms Raake, Dr Johnson, Dr Manning, Dr Eghtesady, and Ms Woodard are affiliated with the Heart Institute; Ms Seger is affiliated with the Pediatric Intensive Care Unit; Dr Boesch is affiliated with the Division of Pulmonary Medicine; Dr Rutter is affiliated with the Division of Otolaryngology; Dr Chima is affiliated with the Division of Critical Care Medicine; and Ms Raake and Ms Seger are also affiliated with the Division of Respiratory Care, Cincinnati Children's Hospital Medical Center, Cincinnati, Ohio.
}

Ms Seger presented a version of this paper at the 26th Annual Children's National Medical Center Symposium on ECMO and Advanced Therapies for Respiratory Failure, held February 21-25, 2010, in Keystone, Colorado. Ms Raake presented a version of this paper at the 56th International Respiratory Congress of the American Association for Respiratory Care, held December 6-9, 2010, in Las Vegas, Nevada.

The authors have disclosed no conflicts of interest.

Correspondence: Jenni Raake MBA RRT-NPS, The Heart Institute, Cincinnati Children's Hospital Medical Center, 3333 Burnet Avenue, MLC 1002, Cincinnati OH 45229. E-mail: jenni.raake@cchmc.org.

DOI: $10.4187 /$ respcare. 00948 tracheal rings. The stenosis can extend down to the bifurcation of the trachea. ${ }^{1}$ The condition is often associated with bronchopulmonary and cardiac malformations, including pulmonary agenesis, which is characterized by absence of vascular, pulmonary, and bronchial structures distal to the tracheal bifurcation. Pulmonary agenesis affects approximately 1 in 15,000 children and has a high mortality rate..$^{1,2}$

Congenital defects associated with pulmonary agenesis include cardiac, gastrointestinal, skeletal, vascular, and genitourinary system defects. ${ }^{3}$ This condition can be a component of the VACTERL (vertebral anomalies, anal atresia, cardiac defects, tracheoesophageal fistula, esophageal problems, renal and limb anomalies) association. ${ }^{4}$ Combined, unilateral lung agenesis and long-segment congenital tracheal stenosis is a rare condition with a high mortality rate. ${ }^{5,6}$

Long-segment congenital tracheal stenosis requires surgical repair; the options include pericardial tracheoplasty, tracheal autograft, tracheal resection, and/or slide tracheoplasty. Slide tracheoplasty is advantageous because it avoids the use of graft material, has a high early-extubation success rate, and is associated with better long-term out- 
ECMO, Extubation, and Lung-Recruitment Maneuvers as Rescue Therapy

Table 1. Chronology of Ventilation and Blood Gas Values

\begin{tabular}{|c|c|c|c|c|c|c|c|}
\hline $\begin{array}{c}\text { Postoperative } \\
\text { Day }\end{array}$ & $\begin{array}{c}\text { PIP } \\
\left(\mathrm{cm} \mathrm{H} \mathrm{H}_{2} \mathrm{O}\right)\end{array}$ & $\begin{array}{c}\text { PEEP } \\
\left(\mathrm{cm} \mathrm{H} \mathrm{H}_{2} \mathrm{O}\right)\end{array}$ & $\begin{array}{l}\text { Respiratory } \\
\text { Rate } \\
\text { (breaths } / \mathrm{min} \text { ) }\end{array}$ & $\mathrm{F}_{\mathrm{IO}_{2}}$ & $\mathrm{pH}$ & $\begin{array}{c}\mathrm{P}_{\mathrm{aCO}_{2}} \\
(\mathrm{~mm} \mathrm{Hg})\end{array}$ & $\begin{array}{c}\mathrm{P}_{\mathrm{aO}_{2}} \\
(\mathrm{~mm} \mathrm{Hg})\end{array}$ \\
\hline 0 & 24 & 4 & 30 & 0.60 & 7.32 & 48 & 150 \\
\hline \multirow[t]{2}{*}{1} & 26 & 4 & 30 & 0.60 & 7.38 & 43 & 120 \\
\hline & & & & & 7.20 & 111 & 129 \\
\hline 2 & ND & ND & ND & ND & 7.34 & 72 & 285 \\
\hline 5 & ND & ND & ND & ND & 6.90 & 130 & 236 \\
\hline \multirow[t]{2}{*}{6} & 30 & 8 & 25 & 0.60 & 7.38 & 68 & 35 \\
\hline & 20 & 5 & 10 & 0.60 & 7.45 & 46 & 49 \\
\hline 12 & 6 & 5 & 5 & 0.40 & 7.46 & 48 & 45 \\
\hline \multirow[t]{2}{*}{13} & 12 & 5 & 10 & 0.50 & 7.38 & 49 & 57 \\
\hline & $\begin{array}{l}\text { Mean Airway Pressure } \\
\left(\mathrm{cm} \mathrm{H}_{2} \mathrm{O}\right)\end{array}$ & $\begin{array}{l}\text { Frequency } \\
(\mathrm{Hz})\end{array}$ & Power & $\mathrm{F}_{\mathrm{IO}_{2}}$ & $\mathrm{pH}$ & $\begin{array}{c}\mathrm{P}_{\mathrm{aCO}_{2}} \\
(\mathrm{~mm} \mathrm{Hg}) \\
\end{array}$ & $\begin{array}{c}\mathrm{P}_{\mathrm{aO}_{2}} \\
(\mathrm{~mm} \mathrm{Hg}) \\
\end{array}$ \\
\hline 14 & 15 & 6 & 5.0 & 0.60 & 7.54 & 37 & 58 \\
\hline 15 & 20 & 8 & 5.0 & 0.60 & 7.54 & 38 & 57 \\
\hline 18 & 20 & 6 & 2.8 & 0.40 & 7.42 & 32 & 199 \\
\hline \multirow[t]{2}{*}{19} & 26 & 6 & 4.0 & 0.60 & 7.38 & 46 & 99 \\
\hline & $\begin{array}{c}\text { PIP } \\
\left(\mathrm{cm} \mathrm{H} \mathrm{H}_{2} \mathrm{O}\right)\end{array}$ & $\begin{array}{c}\text { PEEP } \\
\left(\mathrm{cm} \mathrm{H}_{2} \mathrm{O}\right)\end{array}$ & $\begin{array}{c}\text { Respiratory } \\
\text { Rate } \\
\text { (breaths/min) }\end{array}$ & $\begin{array}{c}\mathrm{F}_{\mathrm{IO}_{2}} \\
\%\end{array}$ & $\mathrm{pH}$ & $\begin{array}{c}\mathrm{P}_{\mathrm{aCO}} \\
(\mathrm{mm} \mathrm{Hg})\end{array}$ & $\begin{array}{c}\mathrm{P}_{\mathrm{aO}_{2}} \\
(\mathrm{~mm} \mathrm{Hg})\end{array}$ \\
\hline 24 & 24 & 10 & 20 & 0.60 & 7.51 & 37 & 184 \\
\hline $\begin{array}{l}\text { PIP }=\text { peak inspira } \\
\text { ND }=\text { no data ava }\end{array}$ & & & & & & & \\
\hline
\end{tabular}

comes. ${ }^{7,8}$ However, despite improvements in surgical techniques, slide tracheoplasty has risks for important complications. ${ }^{9}$

We report successful management of a patient with unilateral (right) pulmonary agenesis and long-segment tracheal and left bronchial stenosis, and who had tracheal dehiscence of the anastomosis site following slide tracheoplasty.

\section{Case Report}

This study was approved by the institutional review board of Cincinnati Children's Hospital Medical Center, Cincinnati, Ohio. The study was not categorized as human research, so informed consent was deemed unnecessary.

A female infant delivered at 36 weeks gestational age had respiratory distress shortly after birth. Breath sounds were absent over the right lung, and she had an imperforate anus. Workup revealed agenesis of the right lung, long-segment congenital tracheal stenosis, external compression of the trachea by the aorta and aortic arch, dextrocardia, a patent ductus arteriosus, an atrial septal defect, and VACTERL association.

In the immediate neonatal period she underwent a colostomy, requiring 3 days of high-frequency oscillatory ventilation (HFOV) postoperatively. She was extubated to nasal CPAP and then transitioned to supplemental oxygen via nasal cannula. She was then transferred to our institution for further evaluation and management of long-segment tracheal stenosis.

At 5 weeks of age she underwent a slide tracheoplasty, extending from the $3 \mathrm{rd}$ tracheal ring down the left main bronchus to the bifurcation of the left upper and lower lobes. Surgery, via mid-sternotomy, used cardiopulmonary bypass support via direct cardiac cannulation. Table 1 shows the chronology of ventilation and blood gas values. Postoperatively she was ventilated (Servo-i, Maquet, Bridgewater, New Jersey) with pressure control synchronized intermittent mandatory ventilation for strict control of peak inspiratory pressure (PIP). Ventilator settings were PIP $26 \mathrm{~cm} \mathrm{H}_{2} \mathrm{O}$, PEEP $4 \mathrm{~cm} \mathrm{H}_{2} \mathrm{O}$, and respiratory rate 30 breaths/min.

On postoperative day 2 she was extubated but quickly developed respiratory distress. Despite high-flow nasal cannula therapy, nasal-mask CPAP, and bronchodilator therapy, she required re-intubation. Flexible bronchoscopy revealed thick secretions, tracheal-wall edema, and obstruction at the repaired tracheo-bronchus and her hypoplastic left-sided bronchi. A PEEP of $8-10 \mathrm{~cm} \mathrm{H}_{2} \mathrm{O}$ was required to maintain airway patency. 


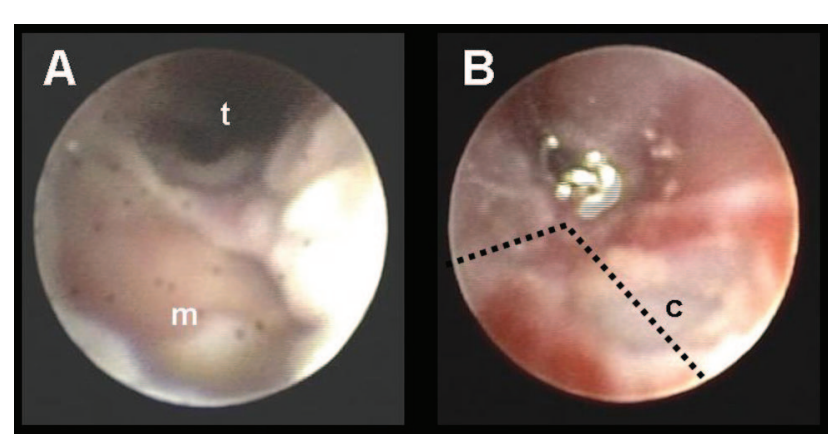

Fig. 1. A: Bronchoscopic view through the anastomosis defect on the left side of the trachea shows the tracheal lumen $(t)$ and the mediastinum (m). B: Bronchoscopic view of the distal extent to the anastomosis (dotted lines) where it tapers together before the attachment to the left main bronchus. Note the "funnel" effect as the larger trachea attaches to the hypoplastic bronchus, and the mucosal erosion and exposed cartilage (c).

After re-intubation she was ventilated with pressure control synchronized intermittent mandatory ventilation, PIP $27 \mathrm{~cm} \mathrm{H}_{2} \mathrm{O}$, PEEP $8 \mathrm{~cm} \mathrm{H}_{2} \mathrm{O}$, and respiratory rate 30 breaths/min. Repeated episodes of poor chest-wall excursion and hypercarbia required higher ventilator settings and frequent manual ventilation and suctioning. Daily flexible bronchoscopies revealed persistent edema that continued to obstruct her small bronchi.

On postoperative day 5 she had an acute desaturation event that required manual bag ventilation. Assessment revealed absent air entry over the left hemithorax. Bradycardia required chest compressions and a dose of epinephrine, and needle decompression was immediately performed. Radiograph showed a pneumothorax, and flexible bronchoscopy revealed dehiscence of the mid-portion of the tracheal anastomosis, with denudation of tracheal mucosa overlying the distal extent of the repair (Fig. 1).

In view of the tracheal dehiscence, ongoing hypercarbia, and brisk air leak, yet uncompromised cardiac function, we started veno-venous ECMO for respiratory support. The ECMO was via neck cannulation with a 12 French dual-lumen venous cannula. We used a perfusion pump (Stöckert SIII Heart Lung System, Sorin Group, Arvada, Colorado) and a silicone membrane (Medtronic, Minneapolis, Minnesota). The initial pump flows were $0.44 \mathrm{~L} /$ min or $125 \mathrm{~mL} / \mathrm{kg} / \mathrm{min}$, with an oxygen concentration of $0.70 \%$ to the membrane, and $2 \mathrm{~L} / \mathrm{min}$ sweep gas flow. The ECMO settings were per our institutional standard protocol to maintain activated clotting time of $225-245$ seconds, hematocrit $\geq 35 \%$, fibrinogen $\geq 150 \mathrm{~g} / \mathrm{L}$, platelet count $\geq 100,000 / \mu \mathrm{L}$, and mean arterial pressure $\geq 50 \mathrm{~mm} \mathrm{Hg}$.

While on veno-venous ECMO she had poor oxygenation despite inhaled nitric oxide and a high $\mathrm{F}_{\mathrm{IO}_{2}}$. On postoperative day 6 , to optimize her oxygenation and facilitate airway healing, we switched her to veno-arterial ECMO

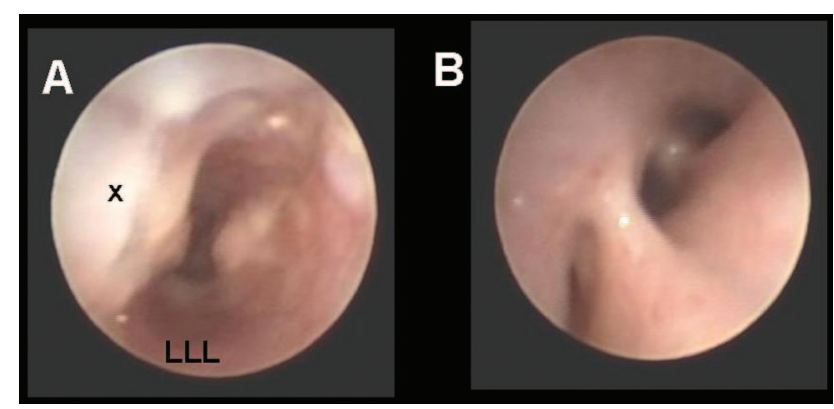

Fig. 2. A: Bronchoscopic view of the mid-trachea at the site of the previous dehiscence $(x)$. There is mild figure-of-eight deformity giving a "dumbbell" shape to the tracheal lumen, which continued to improve without invention. The left-lower-lobe bronchus is hypoplastic and compressed (LLL). B: Resolution of the mucosal edema and clearance of secretions improved the visualization of the left-side bronchi.

and used the same perfusion pump, a 10 French arterial neck cannula, and a single-lumen 14 French venous cannula. After she stabilized on veno-arterial ECMO, we discontinued the nitric oxide and removed the endotracheal tube to avoid any further trauma to the compromised slide tracheoplasty.

She underwent veno-arterial ECMO for 5 days, with an oxygen concentration of $60 \%$ to the membrane, and a sweep gas flow of $0.8 \mathrm{~L} / \mathrm{min}$. Flexible bronchoscopy on postoperative day 12 revealed complete healing (Fig. 2). We re-intubated and placed her on resting ventilator settings: PIP $6 \mathrm{~cm} \mathrm{H}_{2} \mathrm{O}$, PEEP $5 \mathrm{~cm} \mathrm{H}_{2} \mathrm{O}$, respiratory rate 5 breaths/min. Over the next 48 hours we gradually increased the ventilator settings to condition her airway to positive airway pressure. We exercised great caution to safeguard against further dehiscence and to protect her one functional lung. During this period she required repeated suctioning of secretions via flexible bronchoscope and direct bronchial instillation of exogenous pulmonary surfactant (Calfactant, Forest Pharmaceuticals, St Louis, Missouri). Once the ventilator settings reached PIP $13 \mathrm{~cm} \mathrm{H}_{2} \mathrm{O}$, PEEP $10 \mathrm{~cm} \mathrm{H}_{2} \mathrm{O}$, and respiratory rate 10 breaths/min, we began the process of lung recruitment.

On postoperative day 14 we transitioned her to HFOV (3100A oscillator, SensorMedics, Yorba Linda, California) with mean airway pressure $15 \mathrm{~cm} \mathrm{H}_{2} \mathrm{O}$, frequency $6 \mathrm{~Hz}$, and power 5.0. Lung-recruitment maneuvers were performed every 2 hours with a mean airway pressure of $25 \mathrm{~cm} \mathrm{H}_{2} \mathrm{O}$ for 35 seconds. We incrementally increased the HFOV settings to final settings of mean airway pressure $20 \mathrm{~cm} \mathrm{H}_{2} \mathrm{O}$, power 4.0, and frequency $6 \mathrm{~Hz}$. These settings were well tolerated.

As the lungs were recruited we weaned the ECMO flow to $0.09 \mathrm{~L} / \mathrm{min}$ or $25 \mathrm{~mL} / \mathrm{kg} / \mathrm{min}$, and created a shunt through the bridge to increase flow through the circuit while restricting flow to the patient. The ECMO circuit blender was decreased to room air, and the sweep gas flow was 
decreased to $0.2 \mathrm{~L} / \mathrm{min}$. On postoperative day 19 , we decannulated her from ECMO. She remained on HFOV for an additional 5 days before transitioning to conventional mechanical ventilation. She was successfully extubated on postoperative day 39, transferred out of the ICU on postoperative day 43 , and discharged home on postoperative day 55.

\section{Discussion}

This case provides a look at an unusual patient with long-segment congenital tracheal stenosis and unilateral pulmonary agenesis. Our management involved 2 unique strategies: extubation while on ECMO, and lung-recruitment maneuvers.

Long-segment congenital tracheal stenosis interventions include pericardial tracheoplasty, tracheal autograft, tracheal resection, and slide tracheoplasty..$^{10-12}$ Surgeons at our facility advocate slide tracheoplasty repair because it uses the patient's own tissue and improves the chance of successful early extubation. ${ }^{13}$ This is the first tracheal dehiscence at our institution, after a cumulative experience of over 110 slide tracheoplasties.

Early extubation is practiced because the patient's airway will be more stable and at its widest diameter after the slide tracheoplasty procedure. ${ }^{3,7,12}$ Successful extubation within 48 hours of surgery has occurred in over $52 \%$ of our long-segment congenital tracheal stenosis patients, reducing the need for sedation and paralysis that would be given to protect an intubated patient's airway. ${ }^{13}$ It also reduces the risk of wound necrosis or dehiscence caused by the endotracheal tube lying on a fresh anastomosis. ${ }^{9}$

Despite our experience and the fact that our patient had not been mechanically ventilated since her colostomy, persistent respiratory insufficiency made early extubation unsuccessful. ${ }^{13}$ Her narrowed distal airways made her susceptible to mucus plugging and difficult to ventilate; she required frequent suctioning and daily secretion removal via flexible bronchoscopy.

Intraoperatively, the surgeon "leak tests" the tracheal anastomosis at $35 \mathrm{~cm} \mathrm{H}_{2} \mathrm{O} \cdot{ }^{10,13} \mathrm{We}$ attempted to keep the airway pressure below $35 \mathrm{~cm} \mathrm{H}_{2} \mathrm{O}$, but her ongoing issues with poor chest movement, hypercarbia related to airway narrowing, and excessive secretions necessitated multiple episodes of bag ventilation.

Tracheal dehiscence is rare, life-threatening, a major concern for surgeons performing reconstructive surgeries, and requires rapid intervention. ${ }^{12,14,15}$ Since ECMO has been used to manage long-segment congenital tracheal stenosis before, and our options were limited, we placed our patient on ECMO and extubated to remove the risk of the tube contacting the anastomosis.

Perioperative ECMO for tracheal surgery has been described by Hines and Hansell. ${ }^{16}$ Goldman et al ${ }^{17}$ and Ja- cobs et $\mathrm{al}^{18}$ used ECMO in the preoperative phase. One of their patients with long-segment congenital tracheal stenosis had a tracheal dehiscence and died from mediastinitis. Kunisaki et al ${ }^{19}$ and Huang et $\mathrm{a}^{20}$ used ECMO as a bridge to airway surgery. Clearly, ECMO management of tracheal stenosis is not new, ${ }^{21}$ and the Extracorporeal Life Support Organization's registry data from 2007 to 2010 includes 21 patients who underwent ECMO for tracheal stenosis during that period. The registry data does not specify if those uses of ECMO were preoperative or postoperative, but of those 21 patients, 5 were on veno-venous ECMO, 16 were on veno-arterial ECMO, and the survival rate was $57 \% .^{22}$

Despite risks of bleeding, sepsis, and death associated with ECMO, it seemed to be a reasonable option in our patient because it allowed her airway to recover from the excessive airway pressure needed to adequately ventilate her. ${ }^{23}$ Once optimized on ECMO, she was extubated to remove any tracheal pressure from an endotracheal tube, reduce the risk of further dehiscence, and facilitate healing. There have been isolated reports of pediatric and adult patients extubated on ECMO, with good outcomes. Our report is the first in which the extubation was after slide tracheoplasty. ${ }^{24,25}$

ECMO without positive-pressure ventilation resulted in depletion of lung surfactant and complete lung collapse. ${ }^{26}$ Once her airway healed, we began lung recruitment. Our choice of lung recruitment depended on our patient's airway to tolerate positive airway pressure associated with recruitment maneuvers. Recruitment maneuvers can be performed manually with an anesthesia bag or a mechanical ventilator, and have been found to be safe in critically ill children with sustained inflations at $30-40 \mathrm{~cm} \mathrm{H}_{2} \mathrm{O}$ for 15-20 seconds after ventilator disconnections, suctioning, hypoxemia, or routinely every 12 hours. ${ }^{27}$

Surveys of pediatric and neonatal ICUs describe the use of PEEP, PIP, or a combination of both, and complications are rare with the exception of transient hypotension and desaturation episodes. ${ }^{28}$ Another lung-recruitment option is HFOV with incremental increases in mean airway pressure to achieve the desired oxygen saturation or lung inflation on chest radiograph. ${ }^{29}$ Goldman et al used HFOV to facilitate lung recruitment after repair of long-segment congenital tracheal stenosis, ${ }^{18}$ and HFOV appeared to be beneficial during ECMO.

In comparison to the recruitment options described above, our strategy was very conservative, due to concern that higher peak pressure would result in another dehiscence. We opted for "gentle" ventilation, flexible bronchoscopy with suctioning, and surfactant instillation. Once we reached a certain pressure threshold, we did not want to expose her airway to the wide pressure swings required before her dehiscence, which could have harmed the anastomosis, so we transitioned to HFOV. 
On HFOV we slowly increased the mean airway pressure from $15 \mathrm{~cm} \mathrm{H}_{2} \mathrm{O}$ to $20 \mathrm{~cm} \mathrm{H}_{2} \mathrm{O}$ to optimize lung expansion while she was being supported on ECMO. While she was on both HFOV and ECMO (postoperative days 1517), every 2 hours we administered sustained inflations at $25 \mathrm{~cm} \mathrm{H}_{2} \mathrm{O}$ for 35 seconds. After ECMO decannulation we continued using a conservative ventilation strategy, keeping her on HFOV for 5 days before transitioning to conventional ventilation.

Selective use of ECMO, extubation, and slow lung recruitment following tracheal dehiscence avoids some of the risks associated with the standard therapy (mechanical ventilation and aggressive suctioning) and may be useful for rescue therapy when such complications arise.

\section{REFERENCES}

1. Eroglu A, Alper F, Turkyilmaz A, Karaoglanoglu N, Okur A. Pulmonary agenesis associated with dextrocardia, sternal defects and ectopic kidney. Pediatric Pulmonol 2005;40(6):547-549.

2. Nazir Z, Qazi SH, Ahmed N, Atiq M, Billoo AG. Pulmonary agenesis-vascular airway compression and gastroesophageal reflux influence outcome. J Pediatr Surg 2006;41(6):1165-1169.

3. Chou A, Huang SC, Chen SJ, Huang PM, Wang JK, Wu MH, et al. Unilateral lung agenesis: detrimental role of surrounding vessels. Pediatr Pulmonol 2007;42(3):242-248.

4. Lang FJ, Hurni M, Monnier P. Long-segment congenital tracheal stenosis: treatment by slide-tracheoplasty. J Pediatr Surg 1999;34(8): 1216-1222.

5. Backer CL, Kelle AM, Mavroudis C, Rigsby C, Kaushal S, Holinger LD. Tracheal reconstruction in children with unilateral lung agenesis or severe hypoplasia. Ann Thorac Surg 2009;88(5):624-631.

6. Weber T, Connors R, Tracy T. Congenital tracheal stenosis with unilateral pulmonary agenesis. Ann Surg 1991;213(1):70-74.

7. Matúte JA, Romera R, Garcia-Casillas MA, deAgistin JC, Marhuenda C, Berchi FJ, Vazquez J. Surgical approach to funnel shaped congenital tracheal stenosis. J Pediatr Surg 2001;36(2):320-323.

8. Kutlu CA, Yeginsu A, Ozalp T, Baran R. Modified slide tracheoplasty for the management of tracheobronchopathia osteochondroplastica. Eur J Cardiothorac Surg 2002;21(1):140-142.

9. Pinsonneault C, Fortier J, Donati F. Tracheal resection and reconstruction. Can J Anesth 1999;46(5):439-455.

10. Grillo HC, Wright CD, Vlahakes GJ, MacGillivray TE. Management of congenital tracheal stenosis by means of slide tracheoplasty or resection and reconstruction, with long-term follow-up of growth after slide tracheoplasty. J Thorac Cardiovasc Surg 2002;123(1): $145-152$.

11. Hasaniya N, el Zein CF, Mara S, Barth MJ, Ilbawi M. Alternative approach to the surgical management of congenital tracheal stenosis. Ann Thorac Surg 2006;82(6):2305-2307.

12. Backer CL, Mavroudis C, Gerber ME, Holinger LD. Tracheal surgery in children: an 18 year review of four techniques. Eur J Cardiothorac Surg 2001;19(6):777-784.
13. Manning PB, Rutter MJ, Border WL. Slide tracheoplasty in infants and children: risk factors for prolonged postoperative ventilatory support. Ann Thorac Surg 2008;85(4):1187-1192.

14. Kim HK, Kim YT, Sung SW, Park JD, Kang CH, Kim JH, Kim YJ. Management of congenital tracheal stenosis. Eur J Card Surg 2004; 25(6): 1065-1071.

15. Wright CD, Grillo HC, Wain JC, Wong DR, Donahue DM, Gaissert HA, Mathisen DJ. Anastomosis complications after tracheal resection: prognostic factors and management. J Thorac Cardiovasc Surg 2004;128(5):731-739.

16. Hines MH, Hansell D. Elective extracorporeal membrane support for complex tracheal reconstruction in neonates. Ann Thorac Surg 2003; 76(1):175-179.

17. Goldman AP, Macrae DJ, Tasket RC, Edberg KE, Mellgren G, Herberhold $\mathrm{C}$, et al. Extracorporeal membrane oxygenation as a bridge to definitive tracheal surgery in children. J Pediatr 1996;128(3):386388.

18. Jacobs JP, Elliott MJ, Haw MP, Bailey CM, Herberhold C. Pediatric tracheal homograft reconstruction: a novel approach to complex tracheal stenosis in children. J Thorac Cardiovasc Surg 1996;112(6): 1549-1560.

19. Kunisaki S, Fauza D, Craig N, Jennings R. Extracorporeal membrane oxygenation as a bridge to definitive tracheal surgery in neonates. J Pediatr Surg 2008;43(5):800-804.

20. Huang SC, Wu ET, Chi NH, Chiu SN, Huang PM, Chen YS, Lee YC, Ko WJ. Perioperative extracorporeal membrane oxygenation support for critical pediatric airway surgery. Eur J Pediatr 2007; 166(11):1129-1133.

21. Elliott M, Roebuck D, Noctor C, McLaren C, Hartley B, Mok Q, et al. The management of congenital tracheal stenosis. Int J Ped Otorhinolaryngol 2003;67(Suppl 1):S183-S192.

22. ECMO Registry of the Extracorporeal Life Support Organization (ELSO), Ann Arbor, MI: November, 2010.

23. Kumar TK, Zurakowski D, Dalton H, Talwar S, Allard-Picou A, Duebener F, et al. Extracorporeal membrane oxygenation in pericardotomy patients: factors influencing outcome. J Thoracic Card Surg 2010;140(2):330-336.

24. Korvenoja P, Pitkanen O, Berg E, Berg L. Veno-venous extracorporeal membrane oxygenation in surgery for bronchial repair. Ann Thorac Surg 2008;86(4):1348-1349.

25. Wickiser J, Thompson M, Leavey P, Quinn C, Garcia N, Aquino V. Extracorporeal membrane oxygenation (ECMO) initiation without intubation in two children with mediastinal malignancy. Pediatr Blood Cancer 2007;49(5):751-754.

26. Janssen DJ, Zimmerman LJ, Cogo P, Hamvas A, Bohlin K, Luijendijk IH, et al. Decreased surfactant phosphatidylcholine synthesis in neonates with congenital diaphragmatic hernia during extracorporeal membrane oxygenation. Int Care Med 2009;35(10):1754-1760.

27. Duff JP, Rosychuk RJ, Joffe AR. The safety and efficacy of sustained inflations as a lung recruitment maneuver in pediatric intensive care unit patients. Int Care Med 2007;33(10):1778-1786.

28. Halbertsma F, Vaneker M., Van der Hoeven, J Use of recruitment maneuvers during mechanical ventilation in pediatric and neonatal intensive care units in the Netherlands (letter). Int Care Med 2007; 33(9):1673-1674.

29. Froese A, Kinsella J. High-frequency oscillatory ventilation: lessons from the neonatal/pediatric experience. Crit Care Med 2005;33(Suppl 3):S115-S121. 